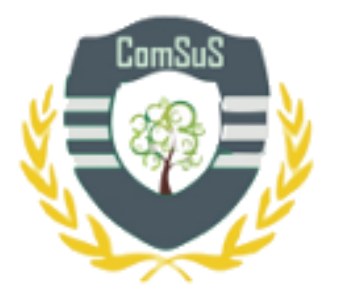

Revista Competitividade e Sustentabilidade - ComSuS Journal of Competitiveness and Sustainability - ComSus e-ISSN:2359-5876

\title{
GESTÃO DE GERAÇÕES EM SISTEMAS BANCÁRIOS
}

\author{
José Augusto Grassi ${ }^{1}$ \\ Marcelo Silva de Andrade ${ }^{2}$ \\ Elza Fátima Rosa Veloso ${ }^{3}$
}

\begin{abstract}
Resumo: Neste artigo apresentamos um estudo da gestão de gerações em sistemas bancários, independente da geração em que o profissional faça parte, o objetivo principal de uma empresa é obter lucro. Para essa finalidade não existe uma receita absoluta, porém, para se estabelecer, ela exige um requisito básico dos colaboradores envolvidos, que é a capacidade de se trabalhar em equipe. Em qualquer que seja a organização multisetorial, nenhum profissional é dotado de todas as competências necessárias a todos os seus processos, desde o atendimento até a produção. A evolução profissional individual sempre depende do aprendizado, que por sua vez depende da troca de experiências e expondo as dificuldades da gestão das pessoas segundo suas gerações. Com o objetivo de entender como as pessoas e as empresas interagem com este assunto e tentam encontrar o equilíbrio em busca da confiança e comprometimento, a fim de buscar soluções para questões como: as pessoas devem adaptar as empresas ou as empresas devem adaptar as novas gerações? Através de estudos teóricos com os conceitos das gerações no Brasil, tivemos o embasamento para utilizar formulários e entrevistas in loco para nossos estudos de caso com duas instituições bancarias, uma federal e outra particular, proporcionando semelhanças e diferenças entre o modo gerir as diferentes gerações.
\end{abstract}

Palavras-Chave: Gestão de Gerações, Gestão de Pessoas, Bancos.

Abstract: This paper presents a study of management generations in banking systems, independent of the generation in which the professional part, the main purpose of a business is profit. For this purpose there is no absolute recipe, however, to be established, it requires a basic requirement of the employees involved, which is the ability to work in teams. In whatever multisectoral organization, no professional is provided with all the necessary skills to all its processes, from customer service to production. The individual professional development always depends on learning, which in turn depends on the exchange of experiences and exposing the difficulties of managing people according to their generations. In order to understand how people and businesses interact with this and try to find the balance in pursuit of trust and commitment in order to seek solutions to questions such as: people should adapt companies or companies must adapt to new generations? Through theoretical studies with the concepts of generations in Brazil, we had the foundation to use forms and interviews on site for our case studies with two banking institutions, one federal and one private, providing similarities and differences between the way managing different generations.

Keywords: Generations Management, People Management, Banks 


\section{INTRODUÇÃO}

Neste artigo será apresentado um estudo sobre gerações e como as empresas de hoje, seja nesta época ou anterior implantadas, tratam a questão de gestão destas gerações desde sua contratação, delegação de funções e relacionamento. Estaremos contextualizando os tipos de gerações, suas características sempre relacionando com o mercado de hoje.

Utilizaremos um dos bancos de crediários de maior expansão no Brasil no seguimento de cooperativas de créditos, unidade específica em Jacutinga-MG, cidade do sul de Minas Gerais, população de 24.648 mil habitantes segundo estimativa do Instituto Brasileiro de Geografia e Estatística [IBGE] (2010), neste caso estaremos questionando a maneira que eles estão gerindo estas gerações e fazendo a ligação com o contexto teórico apresentado.

No entanto, um grupo não é uma equipe. Segundo (Vergara, 2009), "para que um grupo se transforme em equipe, faz-se necessário a presença de um elemento simbólico que o identifique, que uma os participantes, mesmo estando fisicamente distantes”. De fato, o que caracteriza uma equipe é a sua cumplicidade, aceitação das diferenças individuais, respeito mútuo, entendimento da desigualdade de ideias, posturas e condutas de cada membro do grupo. $\mathrm{Na}$ equipe assumem-se riscos, investe-se firmemente no seu desenvolvimento, consideram-se os perfis dos participantes valorizando as diferenças individuais e adequandoas as atividades com o objetivo de melhores resultados, o que torna o trabalho do grupo um autêntico trabalho em equipe.

Com o passar dos anos, tem se observado uma mudança em todas as características no que diz respeito à transformação ou geração de indivíduos, no contexto geral, as mudanças ocorreram pela transformação das gerações, como traços de comportamento, posicionamento, suas qualificações e que o pensar, raciocinar e agir tornou- se mais rápido em virtude ou com a ajuda da globalização e dos avanços tecnológicos na comunicação ou informação.

\section{ORIENTAÇÃO CONCEITUAL}

O entendimento sobre gestão de gerações é abrangente e nos remete a tentar descobrir maneiras e a busca de métodos eficientes e melhor caso para cada situação. Entramos agora num período novo da história, em que os jovens estão a ganhar uma nova autoridade na sua apreensão pré-figurativa do futuro ainda desconhecido. O passado dos adultos é o futuro de cada nova geração; as suas vidas fornecem o plano-base. (Mead, 1970). O crescimento vertiginoso das cidades, a nuclearização da família e a popularização da televisão, além da consolidação de novos valores culturais, tem sido alguns dos fatores mais importantes para o 


\section{GESTÃO DE GERAÇÕES EM SISTEMAS BANCÁRIOS}

distanciamento das gerações e o consequente enfraquecimento da transmissão de conhecimentos de uma geração para a outra. $\mathrm{O}$ futuro das crianças é modelado de tal forma que o que se seguiu depois da infância para os seus antepassados é que elas também experimentarão quando forem crescidas. As culturas pós-figurativas, em que os mais velhos não podem conceber mudanças, e, portanto, apenas podem transmitir aos seus descendentes este espirito de continuidade inalterável, tem estado na base do testemunho actual, característico das sociedades humanas, durante milênios, ou até ao princípio da civilização. (Mead, 1970).

Uma grande quantidade de experiências Inter geracionais tem se dado na área teatral, com resultados bastante positivos.

A gestão vem de gerir que envolve vários processos, desde planejamento, execução, acompanhamento e medidas corretivas, já conceituado pelo Ciclo PDCA que foi criado na década de 20 por Walter A. Shewart, mas foi William Edward Deming, quem disseminou seu uso no mundo todo, por isso, a partir da década de 50, o ciclo PDCA passou a ser conhecido como "Ciclo Deming", a sigla significa, Planejar (Plan), Desenvolver (Do), Checar (Check) e Ação Corretiva (Action). Esta assimetria básica de poder e autoridade é característica ad interação entre diferentes faixas etárias e gerações como um todo. Esta interação pode ser um tanto informal, como no caso de pessoas com pequena diferença de idade entre si (e.g., rapazes mais velhos, etc.); em outros casos pode ser formalizada e oficialmente prescrita. (Eisenstadt, 1976). Quando você envolve pessoas na gestão e não simplesmente processos, alguns problemas aparecerão, pois a intangibilidade, sentimentos e pensamentos são dinâmicos e mutáveis ao decorrer do tempo, as vezes nem historicamente conseguimos observar e chegar em uma conclusão, afinal, são pessoas e estas sentem, produzem e têm atitudes, assim contrasta com o William Edward Deming (1990) que diz "O que não é medido não é gerenciado."

Assim que contratamos uma pessoa, antes funcionário, depois recurso agora colaborador, esperou que estivesse enquadrado nos valores empresariais como a competência da mesma. Veloso et al. (2011) constataram que diferentes grupos de empregados percebem de formas diversas certos aspectos da vida organizacional e são impactados em diferentes graus pelo esforço organizacional em gerenciar pessoas, assim tanto habilidade, conhecimento e atitude, parecem fácil pensar neste tripé conceitual, mas quando colocamos em pauta a maturidade para o mesmo, ou seja, à vontade e os objetivos pessoais começam a tornar um 13 Revista Competitividade e Sustentabilidade - ComSus, Paraná, v. 3, n. 1, p. 11-27, Jan /Jun. 2016. 
pouco mais complicado. Entretanto, Oliveira (2010) descreve que: "É no relacionamento entre as gerações que esta a chave para o resgate do equilíbrio necessário para estes novos tempos".

Falamos em gerações a evolução de algo, pode ser de como assistimos uma televisão, como ouvimos música e também como as pessoas agem e pensam. Segundo (Mannhein, 1993 ) “(...) Geração é um conceito cuja base teórica é sociológica. Define geração como parte do processo histórico que indivíduos da mesma idade-classe compartilham." Quando falamos em gerações, podemos entender que desde o inicio da evolução humana, sempre houve e ocorreram mudanças de gerações. Para Veloso, nenhum dos estudos é longitudinal, logo não é possível distinguir os efeitos da geração dos efeitos da maturidade. Veloso, Silva e Dutra (2011) Logo, em determinados períodos, alguns períodos com a descoberta de renomados cientistas e suas fabulosas inovações e invenções, outras com mudanças demográficas e suas transformações, com as politicas culturais, sociais e outros eventos e acontecimentos, mas o tema a ser tratado só repercutiu após as grandes revoluções em grupo. As oportunidades e as ameaças para as pessoas e para a empresa existentes no mercado de trabalho influenciam as decisões sobre a movimentação.

A compreensão da dinâmica do mercado de trabalho é fundamental para analisarmos o movimento das pessoas na empresa. (Dutra, 2011). Em alguns casos, estudantes prestam serviços voluntários em centros de aposentados e asilo de idosos que prestam ajuda a crianças carentes ou não em escolas primárias e em outros espaços públicos. Há uma profusão de instituições americanas preocupadas em minimizar o distanciamento Inter geracional. Além das universidades, inúmeras entidades governamentais ou não, tem promovido encontros de gerações e também o desenvolvimento mútuo através da coeducação. Há uma série de estudos sobre gerações de pessoas o qual podemos resumir na tabela abaixo:

Tabela 1 - As diferentes gerações e suas características

\begin{tabular}{l|l} 
Gerações & Descrição \\
\multirow{2}{*}{$\begin{array}{l}\text { Veteranos } \\
\text { (1920 e 1945) }\end{array}$} & $\begin{array}{l}\text { Dedicação e sacrifício são as duas palavras-chave para essa geração. As pessoas } \\
\text { seguimento a regras. Aceitam a recompensa tardia e querem estabilidade. Para essa geração, } \\
\text { a honra é muito importante e a paciência é uma virtude. }\end{array}$ \\
\hline Baby Boomer & $\begin{array}{l}\text { São otimistas, querem contagiar, buscam a integração e o envolvimento de todos num } \\
\text { projeto. São profissionais orientados ao trabalho em equipe, ao coletivo. Começa neles a }\end{array}$ \\
\hline 1946 e 1960) & $\begin{array}{l}\text { valorização por aspectos referentes ao bem-estar, saúde e qualidade de vida. É uma geração } \\
\text { muito preocupada com status. Workaholics, trabalham muito e o quanto for preciso. }\end{array}$ \\
\hline Geração X & $\begin{array}{l}\text { São pessoas pragmáticas, práticas e mais confiantes. Buscam o equilíbrio entre vida pessoal } \\
\text { e vida profissional, não querem viver só para o trabalho, apesar de se identificarem muito }\end{array}$
\end{tabular}

14 Revista Competitividade e Sustentabilidade - ComSus, Paraná, v. 3, n. 1, p. 11-27, Jan /Jun. 2016. 
(1961 e 1980) com o trabalho, conforme Veloso p.13. Têm a autoestima mais elevada do que a das gerações anteriores, já começam a questionar autoridades, apesar do respeito que têm por elas.

Esta é a geração do questionamento. Precisa de respostas, e que elas sejam convincentes.

Geração Y

(1981 e 2000)

Lida com autoridade como se não houvesse autoridade, isso é, não cria barreiras na comunicação e no trato com pessoas hierarquicamente elevadas. Busca prazer no trabalho, caso não encontre, muda de trabalho. A maioria foi criada sozinha, então se tornou mais individualista. São grandes negociadores.

Fonte: Kullock \& Santana, (2010)

Para os autores, Meister e Willyerd (2010) todas as gerações foram impactadas por recentes escândalos corporativos, uso de poder político para favorecimento pessoal e outros incidentes antiéticos. Cada geração vai ser reflexo do conjunto criado à sua volta, como explica a presidente do Grupo Foco, Eline Kullock (2010). "A historia define uma cultura, que define um comportamento", aponta. "Somos uma resposta à história e à cultura que foi se desenvolvendo com o passar dos anos", diz a especialista.

\subsection{Uma visão das novas gerações}

Geração Z é a definição sociológica para definir geração de pessoas nascidas na década de 90 até o ano de 2010. A grande nuance dessa geração é zapear. Daí o Z. Alguns especialistas os chamam de Geração Z, uma geração que nasceu sob o advento da internet e do boom tecnológico e para eles estas maravilhas da pós-modernidade não são nada estranháveis. Videogames modernos, computadores cada vez mais velozes e avanços tecnológicos inimagináveis há 25 anos: esta é a rotina dos jovens da Geração Z. são os sucessores da geração $Y$, essa juventude muda de um canal para outro na televisão. Vai da internet para o telefone, do telefone para o vídeo e retorna novamente à internet. Também troca de uma visão de mundo para outra, na vida.

Conheça agora um pouco mais sobre esta denominação, seus membros e seus costumes. Garotas e garotos da Geração Z, em sua maioria, nunca conceberam o planeta sem computador, chats, telefone celular. Por isso, são menos deslumbrados que os da Geração Y. Sua maneira de pensar foi influenciada desde o berço pelo mundo complexo e veloz que a tecnologia engendrou. Diferentemente de seus pais, sentem-se à vontade quando ligam ao mesmo tempo a televisão, o rádio, o telefone, música e internet. Outra característica essencial dessa geração é o conceito de mundo que possui, desapegado das fronteiras geográficas. Para 15 Revista Competitividade e Sustentabilidade - ComSus, Paraná, v. 3, n. 1, p. 11-27, Jan /Jun. 2016. 
eles, a globalização não foi um valor adquirido no meio da vida a um custo elevado. Aprenderam a conviver com ela já na infância. Como informação não lhes falta, está um passo à frente dos mais velhos, concentrados em adaptar-se aos novos tempos.

Enquanto os demais buscam adquirir informação, o desafio que se apresenta à Geração $\mathrm{Z}$ é de outra natureza. Ela precisa aprender a selecionar e separar o joio do trigo. E esse desafio não se resolve com um micro veloz. A arma chama-se maturidade. É nisso, dizem os especialistas, que os jovens precisam trabalhar. Como sempre. Desde o século passado, a forma de classificar gerações de épocas específicas e nomeá-las, tem sido um hábito cada vez mais comum. Diferentemente de separar por idade, sexo ou renda, a classificação por gerações se apresenta mais correta para definir alguém, mesmo com o passar dos anos, pois ela permanece com suas denominações, independente de mudanças pessoais, de faixas etárias ou econômicas. Porém tais classificações não são bem aceitas em todas as áreas do conhecimento, embora amplamente utilizada.

\subsection{A Gestão das Gerações nas Empresas}

É interessante observar que o conhecimento teórico embasado com as psicologias adotado para estudar os perfis das gerações anteriores e de agora, não exclui a dificuldade de trabalhar com as pessoas, às vezes ao contrário, as empresas tendem a adaptar as novas gerações e esquecem-se dos seus principais objetivos, contudo perguntamos, as pessoas devem adaptar as empresas ou as empresas devem adaptar as novas gerações?

Procuramos entender como as pessoas e as empresas interagem neste assunto e tentam encontrar o equilíbrio em busca da confiança e comprometimento. De um lado, está a organização ansiosa por localizar, atrair e selecionar pessoas com competências adequadas ao negócio; de outro, os candidatos desejosos de serem os eleitos. Portanto, captação e seleção caracterizam-se por ser um processo de mão dupla, que envolve muitas pessoas. (RochaPinto, 2007). Existem empresas de diversos ramos, sejam produtos, serviços ou ambos os setores, também podemos enquadrar em ramos de atuações como alimentícios, educacionais, indústrias, agriculturas, financeiros, saúde, entre outros, mas o que não pode diferenciar é que todos precisam de pessoas, ou recursos humanos, ou capital intelectual, ou talentos, hoje em dia até para explicar o que uma pessoa representa dentro da empresa é complicado.

Para Mead, (1970), é certo que a continuidade de todas as culturas depende da presença viva de pelo menos três gerações. A característica essencial das culturas pósfigurativas é a suposição expressa pelos membros da geração mais velha em todos os actos de 


\section{GESTÃO DE GERAÇÕES EM SISTEMAS BANCÁRIOS}

que a sua forma de vida (embora muitas mudanças se tenham dado nela) é imutável, eternamente a mesma. No passado, antes de se ter alargado tanto o âmbito de vida. Os bisavôs eram muito raros e os avós poucos. As pessoas pertencem a uma cultura, uma educação e são decorrentes de elos sociais, tudo isso diferencia uma pessoa da outra em pensamentos, sentimentos e atitudes, cada um dos fatores transformam a vida desta pessoa no conhecimento e atitudes, nos trazendo a capacidade de comunicar, adaptar e tentar aceitar a diferença entre uns e outros.

O processo de evolução da gestão de pessoas no Brasil é marcado por características legais e pelo referencial taylorista. É com esse pano de fundo que os dirigentes empresariais e profissionais especializados foram formados. Durante a década de 80, algumas empresas foram demandando novos conceitos e instrumentos de gestão, mas o desconforto com essas questões só se consolida nos últimos anos da década de 90. (Dutra, 2011). No Brasil, culturalmente temos diferenças notáveis no ambiente interno empresarial, a final, um pais com cerca de 7 (sete) mil quilômetros de costa marítima é imprescindível que temos culturas diversas, muitas vezes já aprendemos a aceitar essas diferenças, são anos de convivência.

Apesar de a cultura ser um dos problemas enfrentados no dia a dia das empresas pelo motivo da adaptação e relacionamento, é de fato um problema já administrado por muitos anos e de difícil mudança, pois a cultura social é algo construído a milhares de anos, e isso já não acontece com as gerações, a mudança é inevitável, e problemas acontecem e acontecerão, o desafio é como as empresas estão gerindo estas mudanças nas gerações.

O novo mundo de negócios, que envolve cada vez mais um número maior de organizações, está dando lugar a profundas modificações na natureza do trabalho e nas relações entre as empresas e seus colaboradores, configurando uma nova situação que gera importantes implicações para a gestão de pessoas. Essa situação reflete-se em um novo mundo de trabalho, cada vez mais caracterizado pela crescente convivência do emprego clássico com um novo tipo de emprego. (Teixeira, 2010). Em estudos já realizados, vimos que em 50 anos passamos por mais de 3 gerações diferentes, as empresas que estão em atividade por esse período passaram por diversas etapas na gestão de pessoas. Para Kanaane (2011) o desenvolvimento organizacional assumirá um caráter estratégico, implicando na captação, fixação e desenvolvimento das equipes, com a finalidade de valorização profissional, fortalecendo as relações interpessoais a partir de autonomia e responsabilidade, visando melhores resultados organizacionais. Essas etapas mostraram que a maneira de pensar e o agir 17 Revista Competitividade e Sustentabilidade - ComSus, Paraná, v. 3, n. 1, p. 11-27, Jan /Jun. 2016. 
das pessoas mudaram e contudo a forma de trabalhar e vem mudando, fazendo menos e pensando mais.

Estamos vendo também acontecer, pessoas de 20 (vinte) a 30 (trinta) anos hierarquicamente maior posicionados do que pessoas de 50 (cinquenta) a 60 (sessenta) anos, pelo motivo de ter qualificações e especialidades que o mercado impõe hoje.

\subsection{As Gerações no Brasil}

No Brasil os estudos sobre as gerações causam grandes discrepâncias em relação às pesquisas realizadas, pois na maioria delas são americanas. Mas, para Veloso, Dutra, Nakata (2008), os Baby Boomers são aqueles nascidos entre 1946 e 1964, a geração X com nascimentos entre 1965 e 1977 e aqueles nascidos a partir de 1978, definidos como a geração Y. Todavia, pertencer a uma mesma geração determina certos pensamentos e comportamentos. Mannheim (1952) nota que não se pode considerar uma geração como um grupo concreto, como uma família ou uma tribo, já que não possui uma estrutura organizacional visível. Para Lombardia (2008) a geração X se presenciou a Guerra Fria, a queda do muro de Berlim, o surgimento de AIDS e as mudanças de conceitos onde não tem padrões rígidos e vivenciaram em expansões tecnológicas. Obviamente, tampouco a ideia de classe de idade se confunde com o conceito de classe social, já que neste caso, os indivíduos são identificados pelo lugar que ocupam nas relações de produção de uma sociedade complexa e com esse tipo de estratificação, como a nossa. Seus membros pensam e atuam de certo modo porque ocupam o mesmo lugar em uma estrutura global. Por outro lado, a geração Y aprende coisas novas muito rapidamente, têm muitas ideias e disposição para realizá-las. Uma geração se constitui a partir de uma mesma locação de indivíduos em determinado contexto social e dentro de um mesmo processo histórico.

Os membros do mesmo grupo apresentam certas similaridades apenas porque suas primeiras e cruciais experiências colocam-nos em contato com as mesmas coisas. Ao mesmo tempo, grupos de jovens e velhos experimentam os mesmos acontecimentos em uma dada sociedade, mas os efeitos desses eventos serão diferentes, dependendo se forem experimentados pela primeira vez ou dentro de um quadro já formado de experiências semelhantes.

Como vimos acima as gerações são determinadas quando há uma transformação sensitiva pela sociedade, portanto nossas transformações são diferentes dos americanos. 


\section{GESTÃO DE GERAÇÕES EM SISTEMAS BANCÁRIOS}

Alguns estudiosos apontam as nossas revoluções sociais e culturais como grandes fatores de mudanças conforme a tabela abaixo:

Tabela 2 - Comparativo das gerações americanas e brasileiras

\begin{tabular}{|l|l|l|l|}
\hline Estados Unidos & Ano (Início - Fim) & Brasil & Geracão \\
\hline Geração & $25-42$ & Revolucionários & Ano (Início - Fim) \\
\hline Silenciosa & $43-60$ & Bossa Nova & $48-66$ \\
\hline Baby Boomers & $61-81$ & Caras Pintadas & $67-84$ \\
\hline Geração X & $82-04$ & Globalizados & $85-06$ \\
\hline Geração Y & $05-$ & Colaborativa & $07-$ \\
\hline Homelanders & & &
\end{tabular}

Fonte: Adaptado de Faustini, V. (2015)

Uma das grandes pesquisadoras das gerações no Brasil foi Helena Cordeiro, ela estudou a evolução histórica e cultural e situou as gerações segundo a nomenclatura americana da seguinte forma:

Tabela 3 - As Gerações no Brasil

\begin{tabular}{|l|l|}
\hline Geração & $\begin{array}{l}\text { Principais aspectos históricos, econômicos, tecnológicos, políticos e culturais } \\
\text { no Brasil }\end{array}$ \\
\hline $\begin{array}{l}\text { Veteranos } \\
(1920 \text { a 1944) }\end{array}$ & Revolução de 30, Era Vargas, Criação das leis de trabalho. \\
\hline $\begin{array}{l}\text { Baby Boomers } \\
(1945 \text { a 1960) }\end{array}$ & $\begin{array}{l}\text { Protesto contra a ditadura militar, milagre econômico, crash da bolsa de valores } \\
\text { de Nova Iorque, emancipação das mulheres. }\end{array}$ \\
\hline $\begin{array}{l}\text { Geração X } \\
(1961 \text { a 1980) }\end{array}$ & $\begin{array}{l}\text { Filosofia yuppie, movimento punk, cresceram vendo televisão, influência da } \\
\text { cultura americana devido a abertura do mercado, surgimento da AIDS, aumento } \\
\text { da violência e do uso de drogas, fracasso para o controle da inflação. }\end{array}$ \\
\hline $\begin{array}{l}\text { Geração Y } \\
(1981 \text { a ?) }\end{array}$ & $\begin{array}{l}\text { Cresceram com TV a cabo, computadores, internet, telefones celulares, mundo } \\
\text { virtual e global, nativos digitais, marcados pelo 11 de setembro, mundo } \\
\text { globalizado, plano real, aumento do consumo e comércio internacional, altas taxas } \\
\text { de desemprego e privatizações. }\end{array}$ \\
\hline
\end{tabular}

Fonte: Adaptado de Cordeiro et al (2012)

Cordeiro também registrou algumas relações entre as gerações segundo quadro abaixo:

19 Revista Competitividade e Sustentabilidade - ComSus, Paraná, v. 3, n. 1, p. 11-27, Jan /Jun. 2016. 
Tabela 4 - Relações entre as Gerações

\begin{tabular}{|c|c|c|}
\hline Tema & rincipais achados & Fontes \\
\hline 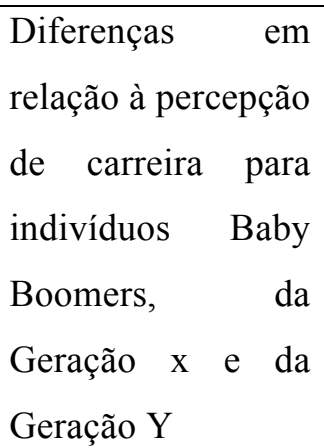 & $\begin{array}{l}\text { Os Baby Boomers se identificam com o trabalho e valorizam } \\
\text { sua rede de contatos para o crescimento profissional mais do } \\
\text { que outras gerações. Comparando a Geração } \mathrm{X} \text { e } \mathrm{Y} \text {, os } \\
\text { indivíduos } \mathrm{X} \text { se identificam mais com o trabalho e os } \mathrm{Y} \\
\text { privilegiam o saber fazer e a rede de contatos. }\end{array}$ & $\begin{array}{l}\text { Veloso, Dutra } \\
\text { e Nakata } \\
(2008) \\
\text { Veloso, Silva } \\
\text { e Dutra (2011) }\end{array}$ \\
\hline $\begin{array}{l}\text { Expectativas em } \\
\text { relação ao trabalho } \\
\text { e a recompensas } \\
\text { tangíveis } \\
\text { intangíveis dos } \\
\text { jovens da Geração } \\
\text { Y }\end{array}$ & $\begin{array}{l}\text { Dentre as expectativas exclusivas da Geração } \mathrm{Y} \text {, foram } \\
\text { identificadas desafios, dinamismo, prazer no trabalho, } \\
\text { flexibilidade, qualidade de vida, reconhecimento, feedback, } \\
\text { bom relacionamento com as pessoas, bom ambiente e o } \\
\text { interesse em trabalhar em uma organização socialmente } \\
\text { responsável. }\end{array}$ & $\begin{array}{l}\text { Cavazotte, } \\
\text { Lemos e } \\
\text { Viana (2010) }\end{array}$ \\
\hline $\begin{array}{l}\text { Análise do } \\
\text { comprometimento } \\
\text { organizacional } \\
(\mathrm{CO}) \quad \text { entre }\end{array}$ & $\begin{array}{l}\text { Indivíduos da Geração Y apresentam níveis mais baixos de } \\
\text { comprometimento organizacional do que os da Geração X em } \\
\text { diversas bases. }\end{array}$ & $\begin{array}{l}\text { Nogueira, } \\
\text { Lemos } \\
\text { Cavazotte } \\
(2011)\end{array}$ \\
\hline $\begin{array}{l}\text { diferentes gerações } \\
\text { por meio da Escala } \\
\text { de Bases CO } \\
(\text { EBACO) }\end{array}$ & $\begin{array}{l}\text { As diferenças geracionais nao impactam nas bases de } \\
\text { comprometimento, mas apontam bases de comprometimento } \\
\text { predominantes. }\end{array}$ & $\begin{array}{l}\text { Vale, Lima e } \\
\text { Queiroz } \\
\text { (2011) }\end{array}$ \\
\hline
\end{tabular}

Fonte: Adaptado de Cordeiro et al (2012)

As empresas, sempre interessadas com o tipo de público que querem atingir, fazem diversas pesquisas de mercado para saberem qual o produto que a geração Y está interessada, como eles querem ser atendido, o que eles estão procurando, pois é um público geralmente muito exigente, sempre antenado em novas tecnologias e novos produtos. Gestores não entendem a geração Y. Diz Pesquisa - Folha de São Paulo, 48\% dos executivos acham que a geração y é mais difícil de recrutar. O estudo foi realizado e de acordo com os entrevistados 55\% são também os mais complicados para retenção e a principal dificuldade é por conta do crescimento profissional. Segundo Sidney de Oliveira (2010) autor do livro Serie Geração Y. A geração $Y$ não tem dificuldades em apresentar suas expectativas, mas a falta de 20 Revista Competitividade e Sustentabilidade - ComSus, Paraná, v. 3, n. 1, p. 11-27, Jan /Jun. 2016. 


\section{GESTÃO DE GERAÇÕES EM SISTEMAS BANCÁRIOS}

referenciais mais comprometidos estabelece atitudes e comportamentos que precisam de um novo foco. Muitos esperam das empresas contratantes ascensão profissional imediata. Segundo o autor os gestores acham que os jovens esperam Status e a chance de subir rápido na empresa, já os jovens esperam a chance de criar, inovar e assumir novos desafios.

Pesquisadores como Veloso, questionam a presença da geração Y no Brasil, conforme seu artigo, Veloso et al (2008) afirmam que "os estudos relacionados à carreira devem considerar não somente a estrutura oferecida pela organização para a ascensão profissional, mas também as diversas ambições, que são específicas da faixa etária do trabalhador". Neste caso, a autora menciona a importância de olhar para os aspectos necessários da carreira.

Está é a geração das pessoas que nasceram após os anos 80, são as pessoas conhecidas também por serem chamadas de geração do milênio ou geração da Internet, que surgiu exatamente por essa época. A geração $\mathrm{Y}$ é conhecida por ser uma geração que vivenciou muitos avanços tecnológicos, crescimento de diversos países, que acabaram tornando-se potências mundiais. As crianças dessa geração cresceram tendo o que muitos de seus pais não tiveram como TV a cabo, videogames, computadores, vários tipos de jogos, e muito mais. Por terem esse contato todo com a tecnologia, acabaram ficando conhecidos por serem pessoas folgadas, distraídas, insubordinadas e superficiais, em sua grande parte.

A Geração Y também é conhecida por ter grande ambição, e é normal encontrar jovens dessa geração que trocam de emprego frequentemente, porque no emprego anterior não eram desafiados e não tinham oportunidade de crescer profissionalmente.

\section{METODOLOGIA}

Conforme Severino (2015), “ São várias metodologias de pesquisa que podem adotar uma abordagem qualitativa, modo de dizer que faz referência mais a seus fundamentos epistemológicos do que propriamente a especificidades metodológicas", e através dessas informações e conceitos, utilizamos os recursos e materiais disponíveis, como livros e revistas científicas, anais de congresso, documentos da própria Instituição de Ensino, dissertações, e realizamos um estudo de campo utilizando o método da entrevista com especialista, com base nos resultados fizemos uma reflexão segundo as pesquisas teóricas realizadas sobre o tema.

21 Revista Competitividade e Sustentabilidade - ComSus, Paraná, v. 3, n. 1, p. 11-27, Jan /Jun. 2016. 


\section{ANÁLISE E DISCUSSÃO DOS RESULTADOS}

Para embasar nosso contexto teórico descrito acima, utilizamos um estudo de caso em uma instituição financeira particular e outra federal, que gerenciam vários tipos de gerações.

As empresas públicas através dos concursos sentem obrigadas a aceitar mais as diferenças de gerações mas isso não significa que não houve impacto na maneira de agir. Segundo nossa entrevista com uma gerente de um banco federal em São Paulo, por mais de 30 anos, a geração de 20 anos atrás eram poucos especialistas e qualificados, assim eram moldados pelo banco, afinal os funcionários tinham tempo para explicar e treinar, era necessário obter o conhecimento no próprio banco e ser acompanhados de perto. Ela também destacou que as pessoas eram mais confiáveis e éticas e a parte da negociação partia mais do cliente do que do próprio banco.

Hoje a geração vem especialista e muito qualificado, jovens acima de tudo, o banco espera que eles já saibam o funcionamento pelo seu conhecimento, não há treinamento e sim uma breve instrução ou no máximo um aprendizado autodidata através de programas de computadores, ela destacou também que hoje o banco necessita de um especialista somente, o negociador, os trâmites burocráticos são realizados rapidamente através da tecnologia, e a parte da negociação hoje em dia parte do banco e não mais dos clientes. Ela complementa, que a falta de ética para cumprir metas são enormes no dia de hoje, pelo fato do banco pressionar nos últimos 15 (quinze) anos neste sentido, e as demissões de justa causa teve elevado número, chegando a 60 (sessenta) por mês.

Já empresas particulares enfrentam o problema de falta de adaptação com um pouco mais agressiva, fazendo o turn over ser o principal fato preocupante, como o tempo é curto, as estratégias devem ser planejadas e executadas a curto prazo, muitas empresas preferem demitir o colaborador que não adaptou do que a empresa adaptar ao colaborador e sua geração.

O caso estudado é o maior sistema financeiro cooperativo do país com mais de 2,9 milhões de associados, 2,2 mil pontos de atendimento, distribuídos em 25 estados e no Distrito Federal. É composto por cooperativas financeiras e empresas de apoio, que em conjunto oferecem aos associados serviços de conta corrente, crédito, investimento, cartões, previdência, consórcio, seguros, cobrança bancária, adquirência de meios eletrônicos de pagamento, dentre outros. Ou seja, tem todos os produtos e serviços bancários, mas não é 


\section{GESTÃO DE GERAÇÕES EM SISTEMAS BANCÁRIOS}

banco. É uma cooperativa financeira, onde os clientes são os donos e por isso os resultados financeiros são divididos entre os cooperados.

A agência estudada fica localizada em Jacutinga, Minas Gerais, cidade de 24.648 mil habitantes segundo estimativa (IBGE, 2010). A agência está instalada a mais de 15 anos, hoje com o quadro de funcionários é setorizado da seguinte maneira: Gerente de Negócios; Assistente de Gerência; Tesoureiro; Agentes de Atendimento; e Caixas, totalizando cerca de 10 funcionários que trabalhando com foco na linha de crédito rural, obtém êxito com os clientes das grandes empresas de Jacutinga e região.

A escolha do ramo financeiro foi realizado pelo fato de além de gerir pessoas os colaboradores também devem ser grandes gestores de pessoas, já que a maior parte de seu tempo é realizado com o cliente, em termos de negociação e parcerias, neste caso queremos demostrar como o fato geração pode ser influenciado desde a contratação até a execução de suas funções.

\subsection{Pesquisa In Loco}

Local: Sistema de Cooperativas de Créditos

Cidade: Jacutinga-MG

Entrevistados: Gerente de Negócios

Data: $18 / 08 / 2015$ a 22/08/2015

\subsubsection{Objetivo da Pesquisa}

A pesquisa foi realizada através de formulários e visita in loco para dar embasamento qualitativo, via estudo de caso à pesquisa realizada segundo o tema gestão de gerações.

\subsubsection{Conclusão do Estudo de Caso}

O estudo de caso nos fez refletir que as gerações são tradadas diferentemente em instituições públicas e privadas, comparando a nossa entrevista com a Gerente de um banco federal e com o Gerente do sistema de cooperativas de créditos.

Por mais que há respeito com as gerações, os diferentes temperamentos, pensamentos e ideologia, trazem um desconforto para a parte estratégica e tática da empresa. Percebemos que as duas entrevistas fazem jus ao respeito, gostam das novas gerações mas elas devem se limitar ao contexto da empresa, ou seja, se moldar aos valores e culturas, no mais, é o mesmo que dizer para uma criança "você pode nadar, mas não molhe.".

Algumas vezes a contradição é bem observada, quando perguntamos sobre o processo de seleção, vimos resposta de análise de curriculum vitae, capacidade intelectual e outras 23 Revista Competitividade e Sustentabilidade - ComSus, Paraná, v. 3, n. 1, p. 11-27, Jan /Jun. 2016. 
competências, e assim que perguntamos se eles preferem algum tipo de geração, algumas respostam dizem que não há destaque, mas exigem um nível de experiência, também vimos uma resposta semelhante quando perguntamos se há quebras de paradigmas quando contratam gerações novas, e a resposta é ambígua novamente, que as gerações novas são bem vindas, mas têm que haver experiência, visto ao fato que as gerações Y não obtém muita experiência no ramo, pois são novos e a única experiência que obtém é meramente teórica, fica a notória que os cargos para o nível tático e estratégico sempre serão baby bommers.

O interessante é analisar que jovens são constatados como espelho de atualização, ou seja, não importa o quão baby boomers se atualizem, estudem e informem, eles sempre serão menos atualizados que as gerações futuras.

Portanto nos estudos de caso percebemos que sim, eles gostam das novas gerações, contudo que fiquem engessados nas diretrizes empresariais e que nem sempre os estudos e atualização são fatores de contratação, ainda contam com o velho paradigma de contratação de experientes.

\section{CONSIDERAÇÕES FINAIS}

O termo gerações é entendido como um conjunto de pessoas comparadas em um mesmo período com um histórico de vida que somam uma troca de experiências e dividem, sempre confrontando a ideais similares, comportamentos distintos, opiniões, ideias, e a forma estruturada de ser. Com a evolução constante e novas tecnologias que diariamente são descobertas, estudos em diversas áreas e vários setores com diferentes pontos de vista, conceituam um dado de pesquisa com base em informações relevantes e estudos que as praticas de adoção de carreiras estando relacionadas com o desenvolvimento pessoal de diversas áreas e diferenças demográficas num contexto geral. Isso tem apresentado que a idade esta diretamente relacionada a um tipo de geração e que existe ou não um envolvimento maior com atividades, com as tarefas, domínio da percepção, capacidade para interagir melhor e um bom desempenho no ambiente organizacional. As mudanças de gerações faz com que a sequência geracional aumente cada vez mais, fazendo uma comparação da organização envolvendo carreira e o seu comprometimento com as tarefas no trabalho, permanecendo neste, por um período maior sem intenção de almejar outro e para cada geração está diretamente ligada a carreiras e oportunidades dentro da organização. Fatores como qualidade de vida, mudanças climáticas, semelhanças genealógicas estão diretamente relacionadas para 


\section{GESTÃO DE GERAÇÕES EM SISTEMAS BANCÁRIOS}

uma nova estratégia organizacional, e que a insegurança, provocada por ondas de downsizing também tem feito muitos profissionais repensarem sobre carreiras e levando algumas gerações a ter maior liderança e autonomia para enxergar o futuro, que em contra partida acaba provocando ou passando uma imagem negativista para uma geração mais conservadora.

Atualmente, muitos líderes das gerações Baby Boomer e X estão se tornando cada vez mais Y. Isso devido ao crescimento exponencial do volume de informações que devem ser consumidas diária e instantaneamente. Embora a maioria dos executivos tenham tido sua formação e inicio de carreira em uma época diferente da de hoje, eles começam a esboçar um novo perfil de comportamento diante de uma nova realidade: ou se envolvem ou serão envolvidos.

Já os mais novos, independente da sua competência e da sua aptidão para o exercício aprimorado de suas funções, precisam atingir o equilíbrio através da sobriedade dos mais velhos. As gerações mais antigas têm a capacidade bem definida de pensar estrategicamente, o que torna suas decisões estatisticamente mais acertadas. Enquanto o jovem pode inovar constantemente por meio das suas ideias os profissionais das gerações anteriores viabilizam a inovação sem os prejuízos que estas podem causar por não terem sido concebidas de maneira estratégica. O comportamento correto (particularmente falando) é aquele que visa o equilíbrio, sem excessos. Um profissional mais velho, mesmo tendendo naturalmente ao conservadorismo, precisa compreender que o mais novo possui os atributos da inovação, já os mais novos, independente da sua competência precisa atingir o equilíbrio através da sobriedade dos mais velhos. Independente da geração que o individuo pertença, o objetivo principal de uma empresa é obter lucro. Em qualquer que seja a organização, nenhum profissional é dotado de todas as competências necessárias a todos os seus processos. A evolução profissional individual sempre depende do aprendizado, que por sua vez depende da troca de experiências.

Portanto, a empresa do futuro se apresentará como aquela que será capaz de conciliar diferentes gerações em um mesmo ambiente de trabalho, extraindo o que cada profissional tem de melhor e equilibrando os potenciais individuais em função do bem estar coletivo. Aprender a evoluir, assumir posições, desenvolver habilidades compatíveis com as exigências do mercado é próprio do ser humano, seja ele da geração X, Y e Z e Boomers. O que muda é a forma, são os caminhos que se trilham, é o conceito de evolução, de aprendizado.

\section{Revista Competitividade e Sustentabilidade - ComSus, Paraná, v. 3, n. 1, p. 11-27, Jan /Jun. 2016.}




\section{REFERÊNCIAS}

Baumotte, A. C. (2013). Trinterano- Gerenciamento de Pessoas em Projetos. $3^{\mathrm{a}}$ Ed. Rio de Janeiro: Editora FGV.

Cordeiro, H. T. O.; Freitag, B. B.; Fischer, A. L.; Albuquerque, L. G. (2013). ReCaPeRevista de Carreiras e Pessoas. São Paulo, V.03, n. 02 Mai/Jun/Jul/Ago.

Deming, W. E. (1990). Qualidade: a revolução da administração. São Paulo: Marques Saraiva.

Dutra, J. S. (1996). Administração de carreiras: Uma proposta para repensar a gestão de pessoas. São Paulo: Atlas.

Dutra, J. S. (2011). Gestão de pessoas: modelo, processos, tendências e perspectivas. 1. ed. 9. reimpr. São Paulo: Atlas.

Eisenstadt S. N. (1976) De geração a geração. São Paulo: Perspectiva.

Half, R. (2012). 48\% dos executivos acham que geração y é a mais dificil de recrutar. São Paulo, Recuperado em 17 outubro, 2015, de http://classificados.folha.uol.com.br/empregos/1175520-48-dos-executivos-acham-quegeracao-y-e-a-mais-dificil-de-recrutar.shtml

Kanaane, R. (2011) Comportamento humano nas organizações: o homem rumo ao século XXI. 2. ed. 13. reimpr. São Paulo: Atlas.

Kullock, E. (2015). O que é geração Y? Disponível em: http://www.focoemgeracoes.com.br/index.php/afinal-o-que-e-geracao-y/. Publicado em: 25 fev. 2010. Acesso em: 20 ago.

Lombardia, P. G. (2008). Quem é a geração Y? HSM Management N 70 P 1-7.

Macedo, I. I. (2012). Gestão de Pessoas. 1. ed. Rio de Janeiro: Editora FVG..

Mannheim, K. (1993). "El problema de las generaciones" [tradução: Ignacio Sánchez de La Yncera], REIS - Revista Española de Investigaciones Sociológicas, n. 62, abr-jun, pp. 193242.

Mead, M. (1970). O conflito de gerações. Lisboa: Brás Monteiro..

Meister, J. C., Willyerd, K. (2010). The 2020 Workplace: How innovative companies attract, develop, and keep tomorrow's employees today. New York: Harper Business. OLIVEIRA, S. (2010). Geração Y. O Nascimento de uma nova versão de Lideres. São Paulo, Intregrare. Editora.

Oliveira, S.R.; Piccinini, V.C.; Bittencourt, B.M. (2012). Juventudes, gerações e trabalho: é possível falar em geração Y no Brasil? Organização \& Sociedade, v.19, n. 62, p.551-558, jul./set.

Revista Brasileira De Orientação Profissional. Jul - dez. 2012, Vol. 13. No. 2, 197-207

Rifkin, J. (1996). O Fim dos Empregos. 2. ed. São Paulo: MakronBooks.

Rocha-Pinto, S. R. (org.). (2007). Dimensões funcionais da gestão de pessoas. 9. ed. rev. ampl. Rio de Janeiro: Fgv. 
Santana, P.; Gazola, J. N. G. (2015). Gestão, comportamento da geração Y. SEMEAD Seminário em Administração. São Paulo, Recuperado em 11 agosto, 2015, de http://www.ead.fea.usp.br/semead /13semead/resultado/trabalhosPDF/995.pdf.

Severino, Antônio Joaquim. (2007). Metodologia do Trabalho Científico. 23. ed. rev. e atual. São Paulo: Cortez.

Teixeira, G. M; (org.). (2010). Gestão estratégica de pessoas. 2. ed. Rio de Janeiro: Fgv.

Veloso, E.F.R.; Dutra, J.S.; Nakata, I.E. (2008). Percepção sobre carreiras Inteligentes: Diferenças entre as Gerações Y, X e Baby Boomers, XXXII Anais do EnAnpad. Rio de Janeiro: Anpad.

Veloso, E. F. R., Dutra, J. S., Fischer, A. L., Pimentel, J. E. A., Silva. R. C., \& Amorim, W. A. C. (2011). Gestão de carreiras e crescimento profissional. Revista Brasileira de Orientação Profissional, 12(1), 61-72.

Veloso, E. F. R.; Silva, R. C. da; Dutra, J. S. (2011). Gerações e Carreira: A Relação entre as Percepções sobre Carreiras Inteligentes e sobre Crescimento Profissional nas Organizações. In: Encontro Nacional da ANPAD - EnANPAD. Anais... p.1-15.

\section{NOTAS}

${ }^{1}$ Mestre em Administração, Pós Graduado MBA em Gestão Empresarial, MBA Internacional em Liderança e Estratégias Empresariais e Engenheiro de Computação. E-mail: jose.grassi@gmail.com

2 Possui graduação em Administração de Empresas pela Universidade Braz Cubas. Especialização em Controladoria Estratégica pela Universidade de Mogi das Cruzes e MBA em Controladoria pela Universidade Anhanguera. Mestrando em Administração pelo Complexo Educacional das Faculdades Metropolitanas Unidas. Especialista em Planejamento e Gestão na Secretaria de Desenvolvimento Econômico. E-mail: msandrade56@yahoo.com.br 3 É graduada, mestre e doutora em Administração. Título de Mestre obtido na Pontifícia Universidade Católica de São Paulo (2003); Doutorado Sanduíche FEA-USP / Northern Illinois University (NIU), com título de Doutor obtido na Faculdade de Economia, Administração e Contabilidade da Universidade de São Paulo (2009), instituição na qual, atualmente, é pós doutoranda, com bolsa FAPESP. E-mail: elzafr@uol.com.br 